Virginia Commonwealth University VCU Scholars Compass

\title{
The effect of variable rest intervals and chronic ankle instability on triplanar ankle motion during performance of the Star Excursion Balance Test
}

Yong Ung Kwon

Youngstown State University

D.S. Blaise Williams III

Virginia Commonwealth University

Follow this and additional works at: http://scholarscompass.vcu.edu/pmr_pubs

Part of the Medicine and Health Sciences Commons

(C) 2017 Elsevier B.V. All rights reserved.

\section{Downloaded from}

http://scholarscompass.vcu.edu/pmr_pubs/8

This Article is brought to you for free and open access by the Dept. of Physical Medicine and Rehabilitation at VCU Scholars Compass. It has been accepted for inclusion in Physical Medicine and Rehabilitation Publications by an authorized administrator of VCU Scholars Compass. For more information, please contact libcompass@vcu.edu. 
Full Length Article

\title{
The effect of variable rest intervals and chronic ankle instability on triplanar ankle motion during performance of the Star Excursion Balance Test
}

\author{
Yong Ung Kwon ${ }^{\mathrm{a}, *}$, D.S. Blaise Williams III ${ }^{\mathrm{b}, \mathrm{c}}$ \\ ${ }^{a}$ Department of Human Performance and Exercise Science, Youngstown State University, Youngstown, OH, United States \\ ${ }^{\mathrm{b}}$ VCU RUN LAB, Department of Kinesiology and Health Sciences, Virginia Commonwealth University, Richmond, VA, United States \\ ${ }^{\mathrm{c}}$ Department of Physical Therapy, Virginia Commonwealth University, Richmond, VA, United States
}

\section{A R T I C L E I N F O}

\section{Article history:}

Received 7 May 2016

Revised 21 December 2016

Accepted 26 January 2017

Available online 12 February 2017

\section{Keywords:}

Kinematics

Multiplanar motion

Coupling ratio

Biomechanics

\begin{abstract}
A B S T R A C T
Inadequate rest intervals may contribute to impaired performance during functional tests. However, the effect of different rest intervals on performance of the SEBT in individuals with and without CAI is not known. Our purposes were to determine whether different rest intervals impact ankle kinematics during the SEBT and whether there differences between those two populations. 24 controls and 24 CAI completed 3 trials in 3 reach directions (anteromedial; AM, medial; M, posteromedial; PM). The order of rest intervals and reach distance were randomized and counterbalanced. Three visits were required to complete the 3 rest interval conditions $(10,20,40 \mathrm{~s})$. Rest interval did not impact ankle kinematics between controls and CAI during the SEBT. Dorsiflexion (DF) (AM:partial $\eta^{2}=0.18$; M:partial $\eta^{2}=0.23$; PM:partial $\eta^{2}=0.23$ ) for all directions and tibial internal rotation (TIR) excursions (AM:partial $\eta^{2}=0.20$ ) for AM direction were greater in individuals with CAI regardless of rest interval length. Rest intervals ranging from 10 to $40 \mathrm{~s}$ did not influence ankle kinematics. Differences exist in DF and TIR between controls and CAI during the SEBT. These findings suggest that clinicians can use any rest interval between 10 and $40 \mathrm{~s}$ when administrating the SEBT. However, triplanar motion differs during a complex functional movement in controls compared to CAI.
\end{abstract}

(c) 2017 Elsevier B.V. All rights reserved.

\section{Introduction}

Ankle injuries are the most common musculoskeletal injury occurring in athletic, military, and physically active individuals (Almeida, Williams, Shaffer, \& Brodine, 1999; Hootman, Dick, \& Agel, 2007). It has been reported that as many as 50\% of high school athletes are diagnosed with an ankle sprain during a given season (Fernandez, Yard, \& Comstock, 2007). Further, $30 \%$ of the individuals with ankle sprains develop chronic ankle instability (CAI), defined as either a feeling of "giving way" at the ankle or recurrent ankle sprains or both (Yeung, Chan, So, \& Yuan, 1994). CAI not only limits an individual's physical activity or activities of daily living, but also results in time lost from sport and high costs for treatment and rehabilitation (Arnold, Wright, \& Ross, 2011).

\footnotetext{
* Corresponding author at: Department of Human Performance and Exercise Science, Youngstown State University, Beeghly Center 307G, Youngstown, OH 44555, United States.

E-mail address: mugika2@gmail.com (Y.U. Kwon).
} 
Some individuals with CAI demonstrate functional ankle instability, which is thought to be characterized by decreased neuromuscular control (Gribble et al., 2013; Riemann, 2002). Neuromuscular control and dynamic postural control can be measured in this population with the Star Excursion Balance Test (SEBT) (Hertel, Braham, Hale, \& Olmsted-Kramer, 2006). The SEBT measures maximum lower extremity reach distances in an attempt to detect functional deficits related to the presence of CAI (Hertel et al., 2006). Further, the SEBT demonstrates high intratester and intertester reliability and validity in healthy populations (Hertel, Miller, \& Denegar, 2000). To reduce the number of components in the SEBT, Hertel et al. examined the SEBT in subjects with and without CAI and found that anteromedial, medial, and posteromedial directions were the most sensitive in identifying deficits associated with CAI (Hertel et al., 2006). Although differences in maximum reach distance between healthy subjects and those with CAI exist, only a few potential factors related to this decreased distance have been established (Hertel et al., 2006).

While previous research has focused on kinematics of the lower extremity as factors that affect performances on the SEBT, most data has been collected in the sagittal plane. Static ankle dorsiflexion range of motion in healthy subjects is significantly related to the performance of the SEBT in the anterior direction, but not in the posteromedial and posterolateral directions (Hoch, Staton, \& McKeon, 2011). Additionally, hip flexion was the strongest predictor of maximum reach distance for the anterolateral and anteromedial directions and knee flexion was strongest predictor for medial, posterior, posterolateral, and posteromedial directions (Robinson \& Gribble, 2008a). Previous studies have only investigated secondary plane motion (frontal and transverse plane) at the hip during the SEBT (Fullam, Caulfield, Coughlan, \& Delahunt, 2014; Hoch et al., 2011; Robinson \& Gribble, 2008a).

Because the foot and lower extremity remain in constant contact with the ground during the entirety of SEBT performance, it is reasonable to assess triplanar motion at both distal and proximal joints. Specifically, with the foot fixed on the floor, the closed-chain movement of the rearfoot for pronation and supination requires significant motion in the secondary planes (Hubbard \& Hertel, 2006; Richie Jr, 2001). These motions are transferred up the chain to the knee and hip through the tibia and are likely to have an effect on performance of the SEBT. To our knowledge, no one has examined coordination of the secondary planes of motion at the ankle (eversion and tibial internal rotation) during the SEBT in healthy and CAI individuals.

During performance of the SEBT, rest intervals of 10 or $15 \mathrm{~s}$ between trials have been reported, although there are no consistent or accepted norms (Hertel et al., 2000, 2006; Linens, Ross, Arnold, Gayle, \& Pidcoe, 2014). Therefore, clinicians may choose variable rest times between trials of the SEBT and this may potentially affect the results and reliability of the test. The relationship between rest interval time and changes in performance on various tasks other than the SEBT has been previously studied (Abt, Siegler, Akubat, \& Castagna, 2011; Dabbs, Munoz, Tran, Brown, \& Bottaro, 2011; Gribble, Hertel, \& Denegar, 2007; Nogueira et al., 2012; Willardson \& Burkett, 2006). Additionally, the presence of CAI may further modify the amount of time needed between trials to be successful on performance of the SEBT.

Therefore, the two purposes of this study were to: (1) assess the impact of different rest intervals on triplanar ankle kinematics (2) to evaluate differences of triplanar ankle kinematics between individuals with and without CAI during performance of the SEBTWe hypothesize was that a shorter rest interval $(10 \mathrm{~s})$ during the SEBT would result in bigger differences in ankle kinematics between healthy individuals and those with CAI compared to a longer rest interval (40 s). We further hypothesize that individuals with CAI will demonstrate reduced angles of ankle kinematics when compared to healthy individuals on the SEBT.

\section{Methods}

\subsection{Participants}

Twenty-four participants with CAI (age: $22.7 \pm 1.6$ years, height: $170.9 \pm 7.2 \mathrm{~cm}$, mass: $65.4 \pm 7.6 \mathrm{~kg}$ ) and 24 uninjured participants (age: $21.9 \pm 2.3$ years, height: $168.4 \pm 6.6 \mathrm{~cm}$, mass: $68.9 \pm 6.5 \mathrm{~kg}$ ) participated. Each group consisted of $12 \mathrm{male}$ and 12 female participants. Uninjured participants' height and weight were matched to those in the CAI group. Chronic ankle instability was operationally defined for this study as repeated episodes of the ankle giving way, regardless of the existence of neuromuscular deficits or pathologic laxity. All participants in the CAI group had unilateral CAI. For inclusion in the CAI group, participants were required to meet the following criteria: (1) regular physical activity defined as at least $3 \mathrm{~h}$ per week of moderate intensity activity (2) a history of at least 1 significant ankle sprain, (3) multiple episodes ( $\geqslant 2$ ) of the ankle giving way within the past 6 months, and/or (4) feeling of instability, (5) free of cerebral concussions, vestibular disorders, and lower extremity injuries for the previous 6 months, and (6) no prior rehabilitation or balance training. For inclusion in the healthy group, participants were required to meet the following criteria: (1) regular physical activity defined as at least $3 \mathrm{~h}$ per week of moderate intensity activity (2) no history of ankle sprain, (3) no episodes of the ankle giving way within the past 6 months, and/or (4) no feeling of instability, (5) free of cerebral concussions, vestibular disorders, and lower extremity injuries for the previous 6 months, and (6) no prior rehabilitation or balance training. In addition, all participants completed the Cumberland Ankle Instability Tool (CAIT) to further confirm ankle instability (Healthy score $=29.0 \pm 2.0$, CAI score $=18.5 \pm 5.0 ; \mathrm{p}<0.001$ ). A score of less than 25 on the CAIT indicates ankle instability (Wright et al., 2013). A score of $\geqslant 28$ indicates a healthy ankle. All participants gave written informed consent approved by the University Institutional Review Board. The rights of the participants were protected. An a priori power analysis $(\alpha=0.05, \beta=0.80)$ performed on sim- 
ilar kinematic variable during SEBT determined that an average of 24 participants per group was necessary $($ range $=15-35$ participants).

\subsection{Procedures}

Participation required a total of 3 visits with 48-h period between each visit. Participants were initially assigned one of the three rest intervals (10, 20 and $40 \mathrm{~s}$ ). This study selected rest intervals that were 2 times greater and 4 times greater than the previously recorded rest interval of $10 \mathrm{~s}$ (Hertel et al., 2006; Linens et al., 2014). These times were considered reasonable clinical rest times. Longer rest times (i.e. $60 \mathrm{~s}$ ) were not selected in an attempt to represent how the test was likely to be performed in the clinic. The order of rest intervals and reach directions (anteriomedial: AM, medial:M, posteriomedial: PM) were randomized and counterbalanced. Specifically, participants performed the three reach directions with a different rest interval on each visit. Participants rode a stationary bike for $5 \mathrm{~min}$ as a warm up exercise before testing. Before recording, participants performed 4 practice trials in each of 3 directions (Robinson \& Gribble, 2008b). After completing four practice trials, the participants performed 3 additional trials in each of 3 directions that were used for analysis (Robinson \& Gribble, 2008b). Participants were not aware of which trials were practiced and which trials were recorded. The investigator used a stopwatch to monitor the rest times between trials and to instruct the participants' start times for each subsequent trial.

\subsection{Instrumentation}

For each direction, kinematic data at the ankle joint was collected at $100 \mathrm{~Hz}$ with a 12-camera infrared motion-capture system (VICON MXF20, VICON Motion System, Centennial, CO) and companion software (Nexus version 1.8.5; VICON Motion Systems). Local coordination systems were established for the shank and foot and kinematic data was calculated and filtered at $12 \mathrm{~Hz}$ with 4 th order recursive Butterworth filter. Reflective markers were attached to the bases of the $1 \mathrm{st}$ and 5 th metatarsal, lateral and medial malleoli, distal, proximal, and lateral heel, lateral and medial epicondyles of the femur and the lateral part of the lower leg (Fig. 1a, b) (Ferber, McClay Davis, Williams, \& Laughton, 2002). Triplanar ankle joint angles for dorsiflexion (DF), eversion (EV) and tibial internal rotation (TIR) were calculated using Visual 3D data analysis software (C-Motion).

\subsection{Star Excursion Balance Test}

Participants stood barefoot in the center of a grid which was formed by 3 lines on the floor. The medial line was perpendicular to the long axis of the foot. The AM line was 45 anterior to the medial line and the PM line was 45 posterior to the medial line. The stance leg was determined in the CAI group as the injured leg and the legs were side-matched in the healthy

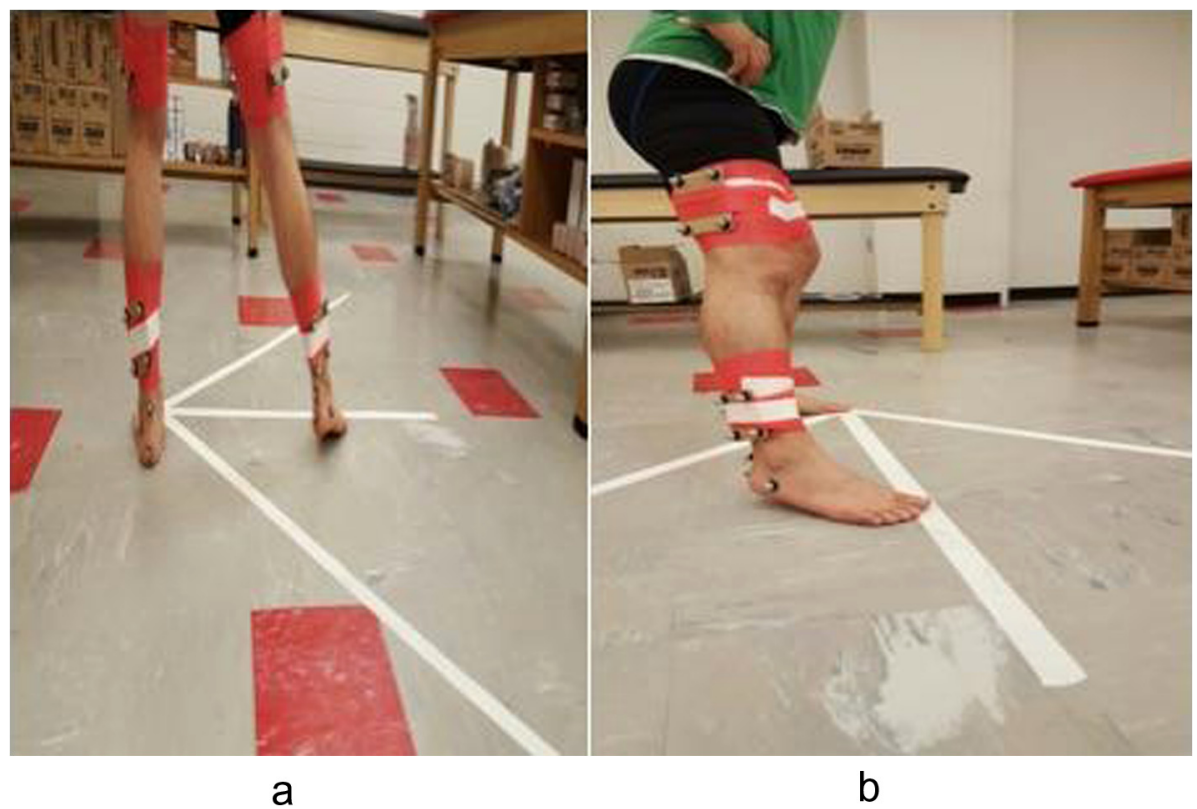

Fig. 1. Subjects performing the Star Excursion Balance Test (SEBT) in the medial direction with segmental tracking markers. 1a. Segmental tracking merkers (posterior view), 1b. Segmental tracking markers (lateral view). 
group. Foot position was controlled by placing the great toe on the center of grid. Participants were instructed to stand in their comfortable double-leg stance before starting the SEBT. The main goal of the performance during the SEBT is to maximally reach distance. Therefore, the participants were then instructed to reach their big toe on their reach side as far as possible along the three lines marked on the floor and to return the reaching toe back to the center of the grid while maintaining a single leg stance on their measured leg.

During SEBT performance, the participants kept their hands on the hips and the entire stance foot remained in contact with the ground. Participants were instructed to lightly touch the line with no transference of weight. Trials were discarded and repeated if participants moved their foot from the original foot position, lost their balance, removed their hands from the hips, or failed to touch the line with the reach foot during the trial. Velocity of the reach side toe marker was used to determine starting and ending points in each direction. Zero velocity indicated the starting point just before the reaching big toe started to move in each reach direction (start) and the farthest reach point (max). Joint angles for DF, EV, and TIR were measured between starting and max points in each direction. Excursion was defined as the difference between initial and peak ankle joint angle. Excursions of DF, EV, and TIR across the 3 directions in the 3 rest interval groups were calculated.

\subsection{Statistical analyses}

The means of 3 trials for DF, EV, and TIR excursions in the 3 reach direction were established. Two-way mixed-model analyses of variance (ANOVA) in each direction (AM, M, PM) were calculated to investigate group effects (CAI and healthy) and rest interval effects $(10,20,40 \mathrm{~s})$ for DF, EV, and TIR (Fig. 1a, b). Post-hoc comparisons using Fisher's Least Significant Difference were performed to assess specific differences when there was a significant difference among population groups (CAI, healthy) or rest interval groups (10 s, 20 s, $40 \mathrm{~s}$ ). Effect sizes (eta-squared) of significant differences for main effects were reported. The level of significance was set at 0.05 for all comparisons.

\section{Results}

\subsection{Dorsiflexion Excursion}

There was no significant main effect for rest interval time (AM: $F_{2,45}=2.63, p=0.08 ; M: F_{2,45}=2.59, p=0.08 ; P M$ : $\mathrm{F}_{2,45}=2.17, \mathrm{p}=0.12$ ). Individuals with CAI showed an increase in DF excursion compared to healthy controls in all 3 reach directions $\left(A M: F_{1,46}=10.1, p=0.003\right.$, partial $\eta^{2}=0.18$ with $90 \%$ CI $[1.51,5.23] ; M: F_{1,46}=14.25, p<0.001, p a r t i a l \eta^{2}=0.23$ with 90\% CI [2.42, 7.75]; PM: $F_{1,46}=14.1, p<0.001$, partial $\eta^{2}=0.23$ with $90 \%$ CI [2.49, 7.43]). There was no significant interaction between CAI groups and rest interval time (AM: $F_{2,45}=1.74, p=0.18 ; M: F_{2,45}=0.80, p=0.45 ; P M: F_{2,45}=0.68, p=0.5$ ). Large effect sizes for all directions indicate large increases in DF excursion in the healthy group compared to the CAI group (Table 1 and Fig. 2).

\subsection{Eversion Excursion}

There was no significant main effect for time across the three rest interval times $\left(A M: F_{2,45}=1.17, p=0.31 ; M: F_{2,45}=0.46\right.$, $\mathrm{p}=0.63 ; \mathrm{PM}: \mathrm{F}_{2,45}=1.37, \mathrm{p}=0.26$ ). When evaluating eversion excursion, there was no main effect when comparing CAI to healthy controls (AM: $\mathrm{F}_{1,46}=0.31, \mathrm{p}=0.57 ; \mathrm{M}: \mathrm{F}_{1,46}=0.35, \mathrm{p}=0.55 ; \mathrm{PM}: \mathrm{F}_{1,46}=4.0, \mathrm{p}=0.051$ ). There was no significant interaction between CAI groups and rest interval time $\left(A M: F_{2,45}=0.26, p=0.77 ; M: F_{2,45}=1.31, p=0.28 ; P M: F_{2,45}=0.23\right.$, $\mathrm{p}=0.79$ ). (Table 2 and Fig. 2).

Table 1

Mean (SD) of dorsiflexion excursion $\left({ }^{\circ}\right)$.

\begin{tabular}{|c|c|c|c|c|c|c|c|c|c|}
\hline \multirow[t]{2}{*}{ Rest interval } & \multicolumn{3}{|l|}{$\mathrm{AM}$} & \multicolumn{3}{|l|}{ M } & \multicolumn{3}{|l|}{ PM } \\
\hline & Healthy & CAI & Mean & Healthy & CAI & Mean & Healthy & CAI & Mean \\
\hline \multirow[t]{2}{*}{$10 \mathrm{~s}$} & 16.1 & 20.8 & 18.5 & 15.5 & 19.9 & 17.7 & 13.2 & 18.7 & 16 \\
\hline & $(6.2)$ & $(4.6)$ & $(5.9)$ & $(6.5)$ & $(5.8)$ & (6.5) & $(5.6)$ & $(4.3)$ & $(5.6)$ \\
\hline \multirow[t]{2}{*}{$20 \mathrm{~s}$} & 17.9 & 19.8 & 18.8 & 16 & 20.1 & 18 & 13.8 & 17.4 & 15.6 \\
\hline & $(7.3)$ & $(6.4)$ & (6.9) & (7) & $(4.9)$ & (6.3) & $(7.8)$ & $(4.8)$ & (6.7) \\
\hline \multirow[t]{2}{*}{$40 \mathrm{~s}$} & 13.7 & 19.5 & 16.6 & 12.6 & 19.1 & 15.8 & 11.5 & 16.7 & 14.1 \\
\hline & $(4.8)$ & $(6.1)$ & $(6.1)$ & (5.9) & $(4.6)$ & $(6.2)$ & $(4.6)$ & $(6.4)$ & (6.1) \\
\hline \multirow[t]{2}{*}{ Mean } & 15.9 & $20^{*}$ & & 14.6 & $19.7^{*}$ & & 12.8 & $17.5^{*}$ & \\
\hline & $(5.4)$ & $(5.3)$ & & $(6.1)$ & $(4.3)$ & & $(5.4)$ & $(4.5)$ & \\
\hline
\end{tabular}

AM: anteromedial, M: medial, PM: posteromedial.

10 s: 10 s group, 20 s: 20 s group, 40 s: 40 s group.

p value <0.05: CAI > Healthy. 


\section{Dorsiflexion}

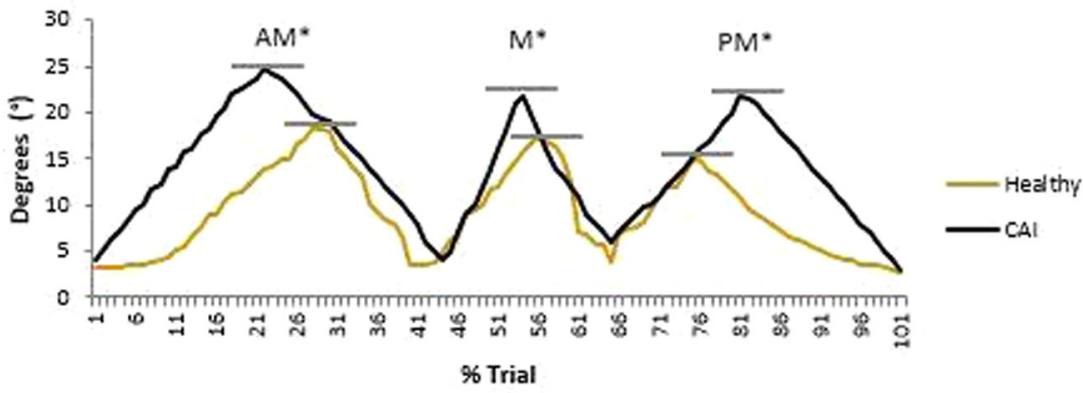

Eversion

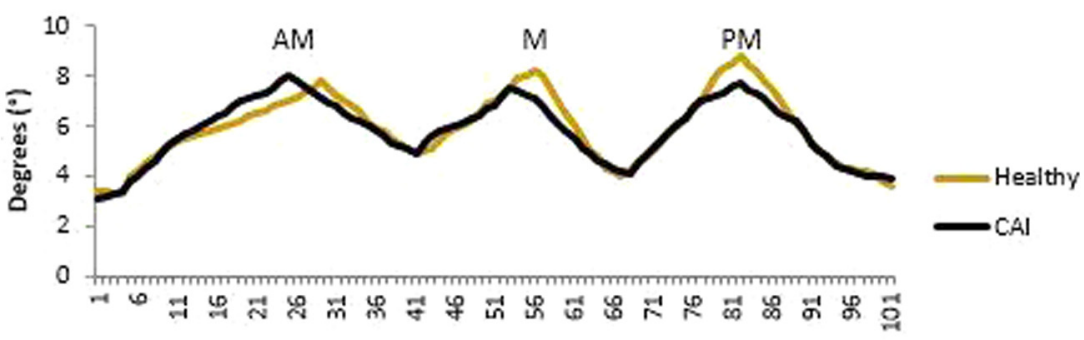

\% Trial

Tibial Internal Rotation

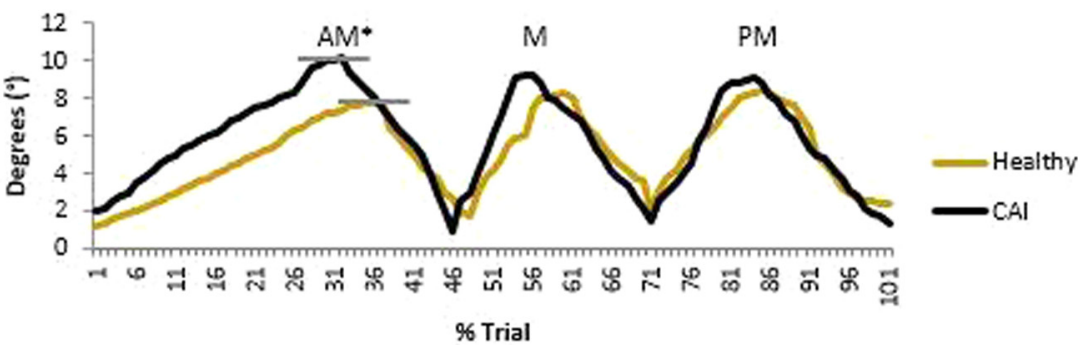

Fig. 2. Excursions of DF, EV, and TIR in AM, M, and PM directions between Individuals with and without CAI. AM: anteromedial, M: medial, PM: posteromedial ${ }^{*} \mathrm{p}$ value <0.05: CAI > Healthy.

Table 2

Mean (SD) of eversion excursion $\left({ }^{\circ}\right)$.

\begin{tabular}{|c|c|c|c|c|c|c|c|c|c|}
\hline \multirow[t]{2}{*}{ Rest interval } & \multicolumn{3}{|l|}{ AM } & \multicolumn{3}{|l|}{ M } & \multicolumn{3}{|l|}{ PM } \\
\hline & Healthy & CAI & Mean & Healthy & CAI & Mean & Healthy & CAI & Mean \\
\hline \multirow[t]{2}{*}{$10 \mathrm{~s}$} & 4.1 & 4.8 & 4.5 & 3.5 & 4 & 3.7 & 4.1 & 3.5 & 3.8 \\
\hline & $(2.9)$ & $(2.7)$ & $(2.8)$ & $(1.8)$ & $(2.8)$ & $(2.3)$ & $(2.8)$ & $(2)$ & $(2.4)$ \\
\hline \multirow[t]{2}{*}{$20 \mathrm{~s}$} & 3.8 & 4 & 3.9 & 4.1 & 3.4 & 3.8 & 4.6 & 3.5 & 4 \\
\hline & $(2.4)$ & $(2.3)$ & $(2.3)$ & $(2.3)$ & $(2.2)$ & $(2.3)$ & $(2.7)$ & (1.5) & $(2.2)$ \\
\hline \multirow[t]{2}{*}{$40 \mathrm{~s}$} & 4.5 & 4.5 & 4.5 & 4.4 & 3.8 & 4.1 & 5 & 3.9 & 4.5 \\
\hline & $(2.4)$ & $(2.3)$ & $(2.4)$ & (3.1) & (2) & $(2.6)$ & $(2.5)$ & (1.6) & $(2.2)$ \\
\hline \multirow[t]{2}{*}{ Mean } & 4.1 & 4.4 & & 4 & 3.7 & & 4.5 & 3.6 & \\
\hline & $(2.2)$ & $(2.3)$ & & $(2.4)$ & $(2.4)$ & & $(2.6)$ & $(1.8)$ & \\
\hline
\end{tabular}

AM: anteromedial, M: medial, PM: posteromedial.

$10 \mathrm{~s}$ : $10 \mathrm{~s}$ group, $20 \mathrm{~s}$ : $20 \mathrm{~s}$ group, $40 \mathrm{~s}$ : 40 s group.

p value $<0.05$ : CAI $>$ Healthy. 


\subsection{Tibial internal rotation excursion}

There was no significant main effect for time across the three rest interval times $\left(A M: F_{2,45}=0.82, p=0.44 ; M: F_{2,45}=1.93\right.$, $\mathrm{p}=0.15$; PM: $\mathrm{F}_{2,45}=1.3, \mathrm{p}=0.28$ ). Finally, when evaluating TIR, individuals with CAI showed an increase in TIR excursion compared to healthy controls in the AM direction. (AM: $F_{1,46}=11.68, p<0.001$, partial $\eta^{2}=0.20$ with $90 \% \mathrm{CI}[0.8,3.2]$; M: $\mathrm{F}_{1,46}=3.48, \mathrm{p}=0.06 ; \mathrm{PM}: \mathrm{F}_{1,46}=1.0, \mathrm{p}=0.30$. There was no significant interaction between CAI groups and rest interval time (AM: $F_{2,45}=2.43, p=0.09 ; M: F_{2,45}=2.16, p=0.12 ; P M: F_{2,45}=0.52, p=0.59$ ). The effect size for the AM direction indicates large increases in TIR excursion in the CAI group compared to the healthy group (Table 3 and Fig. 2).

\section{Discussion}

The results of this study showed that rest intervals up to $40 \mathrm{~s}$ did not influence ankle kinematics during the performance of the SEBT in individuals with and without CAI. However, differences in kinematic patterns (DF and TIR excursions) exist between healthy and CAI individuals regardless of rest intervals. Specifically, individuals with CAI demonstrated greater excursions of DF in all directions and TIR in the AM direction compared to those without CAI.

Contrary to our hypothesis, rest interval time in all directions did not influence DF, EV, and TIR excursions in healthy or CAI individuals during the SEBT. A plausible explanation is that $10 \mathrm{~s}$ may be not short enough to impair recovery or that $40 \mathrm{~s}$ may be not long enough to aid in recovery. It was posited that the shortest rest time $(10 \mathrm{~s})$ might be more likely to cause fatigue particularly in the individuals with impaired neuromuscular function. Because CAI results in impaired lower extremity balance and strength which may be associated with fatigue, rest interval times in this population may have a higher possibility of causing kinematic alterations due to potential fatigue (Gribble, Hertel, Denegar, \& Buckley, 2004; Gribble et al., 2007; Gutierrez, Jackson, Dorr, Margiotta, \& Kaminski, 2007). However, because the rest interval times in the current study did not discriminate between groups, it is likely they were not long enough to result in fatigue in either group. Based on these findings, it appears that varying rest intervals between 10 and $40 \mathrm{~s}$ has no impact on performance on the SEBT.

Interestingly, in the current study, individuals with CAI demonstrated greater DF excursion than healthy individuals in all directions during the SEBT. Previous studies demonstrate that individuals with CAI have increased DF during functional movements such as single leg jump landings, walking, and a step-up tasks (Caulfield \& Garrett, 2002; Hartsell \& Spaulding, 1999). In contrast, it has been observed that individuals with CAI demonstrated deficits in both weight bearing and open chain DF range of motion (Chinn, Dicharry, \& Hertel, 2013; Drewes, McKeon, Kerrigan, \& Hertel, 2009). However, these measurements may not be strong indicators of functional movement due to the controlled nature of the tasks. In individuals without limited passive motion, the need to reach maximum DF (or other motion) during a task is likely not necessary. This may be due to a better neuromuscular control. Further, limited passive ROM does not always result in decreased active ROM especially during a dynamic task. Thus, the SEBT may result in greater dynamic DF ROM as a compensatory motion to maximally reach all direction or loss of control in individuals with CAI. In individuals without CAI, greater DF may not be necessary for maximum reach distance. It is important to note that passive ankle motion was not measured in the current study.

It is possible there is a proprioceptive component to the increase in DF as individuals with CAI who have decreased proprioception are required to move their joint to the end of the available ROM in order to get positional feedback compared to healthy individuals who receive feedback earlier in their ROM. (Willems, Witvrouw, Verstuyft, Vaes, \& De Clercq, 2002) In addition, individuals with CAI underestimate the joint position due to decreased proprioception. Thus, the ankle position may be in greater DF than their perception (Yokoyama, Matsusaka, Gamada, Ozaki, \& Shindo, 2008). Therefore, even if there is a lack of available passive ROM, they utilize more of that available motion in order to maximize joint feedback. This has implications for compression on adjacent joint surfaces during loading and potential inability to accommodate to changes

Table 3

Mean (SD) of tibial internal rotation excursion $\left(^{\circ}\right)$.

\begin{tabular}{|c|c|c|c|c|c|c|c|c|c|}
\hline \multirow[t]{2}{*}{ Rest interval } & \multicolumn{3}{|l|}{ AM } & \multicolumn{3}{|l|}{ M } & \multicolumn{3}{|l|}{ PM } \\
\hline & Healthy & CAI & Mean & Healthy & CAI & Mean & Healthy & CAI & Mean \\
\hline \multirow[t]{2}{*}{$10 \mathrm{~s}$} & 6.7 & 9.1 & 7.9 & 7.2 & 8.4 & 7.8 & 8.7 & 9.8 & 9.3 \\
\hline & (3) & $(2.3)$ & (2.9) & $(2.4)$ & (2.9) & $(2.7)$ & $(2.4)$ & (3.4) & (3) \\
\hline \multirow[t]{2}{*}{$20 \mathrm{~s}$} & 6.5 & 9.3 & 7.9 & 6.9 & 9 & 8 & 8.4 & 8.4 & 8.4 \\
\hline & $(2.5)$ & $(3.6)$ & $(3.4)$ & $(2.5)$ & $(2.6)$ & $(2.8)$ & $(2.9)$ & $(2.4)$ & $(2.7)$ \\
\hline \multirow[t]{2}{*}{$40 s$} & 6.9 & 7.8 & 7.4 & 7 & 6.9 & 6.9 & 8.5 & 9.1 & 8.8 \\
\hline & (3) & $(2.9)$ & (2.9) & $(3.8)$ & $(2.7)$ & (3.3) & (3.3) & $(2.8)$ & $(3.1)$ \\
\hline \multirow[t]{2}{*}{ Mean } & 6.7 & $8.7^{*}$ & & 7 & 8.1 & & 8.5 & 9.1 & \\
\hline & $(2.7)$ & $(2.9)$ & & $(2.8)$ & $(2.5)$ & & $(2.8)$ & $(2.8)$ & \\
\hline
\end{tabular}

AM: anteromedial, M: medial, PM: posteromedial.

10 s: 10 s group, 20 s: 20 s group, 40 s: 40 s group.

p value $<0.05$ : CAI $>$ Healthy. 
instability at the end of the range of motion. While clinicians may focus on improving passive ROM in patients with CAI, it is likely more important to focus on neuromuscular control in midrange and prior to end range during functional activities.

While it was not directly measured in the current study, joint velocity during functional activities likely plays in role in the observed differences. An increased ROM during a similar time frame results in increased joint angular velocities. One method of enhancing joint feedback may be by moving faster through the available ROM, thus activating muscle spindles sensitive to stretch (Proske, 2005). That is, increased joint velocities enhance the sensitivity of the muscle spindle which may improve feedback.

There was no difference in EV excursion between healthy individuals and those with CAI. While the ankle joint moves in multiple planes during the SEBT, minimal frontal plane rearfoot motion occurs as the forefoot and heel are fixed to the surface (Gribble, Hertel, \& Plisky, 2012). Because these reach tasks are biased toward the medial side, EV may not differentiate limitations in CAI subjects who typically have lack of control in the lateral direction. As a result, it is possible that participants with CAI may show differences in ankle inversion during performance of lateral directions of the SEBT even if individuals with CAI have either deficits of or greater eversion than those without CAI.

Finally, the results of the current study indicate that individuals with CAI demonstrate greater TIR excursion only in the AM direction. TIR is the transverse plane motion of the lower leg and may be described as a combination tibial motion in anterior and medial directions (Nawoczenski, Cook, \& Saltzman, 1995). Thus, in order to maximally reach in the AM direction, the tibia needs to move in both planes. This result indicates that AM direction of the SEBT places greater demands on the muscles and joints that control the transverse plane in the lower leg in individuals with CAI compared to healthy individuals. These initial findings on TIR during the performance of the SEBT suggest that rotational motion is an important component of balance during single-leg activities. Further, this appears to be dependent on the direction of reach. For example, activities that require anterior reach (i.e. descending stairs) may require exercises or training focusing on transverse plane control of the ankle.

\section{Conclusion}

Variable rest intervals ranging from 10 to $40 \mathrm{~s}$ did not impact ankle kinematics during the SEBT in individuals with and without CAI. Thus, clinicians and researchers can feel confident with rest intervals between 10 and $40 \mathrm{~s}$ when administering the SEBT. Additionally, individuals with CAI demonstrate greater DF in AM, M, and PM directions and TIR in AM direction during the SEBT. This greater dynamic DF may be associated with a need for greater feedback at the end of available ROM or due to a loss of neuromuscular control. Further examination of the individual contributors to this unique movement pattern is necessary. These differences highlight the need for clinicians to measure both active and passive ankle ROM during rehabilitation of individuals with CAI. These results provide a deeper understanding of specific ankle kinematics during the SEBT.

\section{Conflict of interest statement}

This research did not receive any specific grant from funding agencies in the public, commercial, or not-for-profit sectors.

\section{Acknowledgement}

The Authors would like to thank Dr. Brent Arnold of Indiana University-Purdue University Indianapolis for his help with consultants in this study.

\section{References}

Abt, G., Siegler, J. C., Akubat, I., \& Castagna, C. (2011). The effects of a constant sprint-to-rest ratio and recovery mode on repeated sprint performance. Journal of Strength and Conditioning Research, 25, 1695-1702.

Almeida, S. A., Williams, K. M., Shaffer, R. A., \& Brodine, S. K. (1999). Epidemiological patterns of musculoskeletal injuries and physical training. Medicine and Science in Sports and Exercise, 31, 1176-1182.

Arnold, B. L., Wright, C. J., \& Ross, S. E. (2011). Functional ankle instability and health-related quality of life. Journal of Athletic Training, 46, 634-641.

Caulfield, B. M., \& Garrett, M. (2002). Functional instability of the ankle: Differences in patterns of ankle and knee movement prior to and post landing in a single leg jump. International Journal of Sports Medicine, 23, 64-68.

Chinn, L., Dicharry, J., \& Hertel, J. (2013). Ankle kinematics of individuals with chronic ankle instability while walking and jogging on a treadmill in shoes. Physical Therapy in Sport, 14, 232-239.

Dabbs, N. C., Munoz, C. X., Tran, T. T., Brown, L. E., \& Bottaro, M. (2011). Effect of different rest intervals after whole-body vibration on vertical jump performance. Journal of Strength and Conditioning Research, 25, 662-667.

Drewes, L. K., McKeon, P. O., Kerrigan, D. C., \& Hertel, J. (2009). Dorsiflexion deficit during jogging with chronic ankle instability. Journal of Science and Medicine in Sport, 12, 685-687.

Ferber, R., McClay Davis, I., Williams, D. S., 3rd, \& Laughton, C. (2002). A comparison of within- and between-day reliability of discrete 3D lower extremity variables in runners. Journal of Orthopaedic Research, 20, 1139-1145.

Fernandez, W. G., Yard, E. E., \& Comstock, R. D. (2007). Epidemiology of lower extremity injuries among U.S. high school athletes. Academic Emergency Medicine, 14, 641-645.

Fullam, K., Caulfield, B., Coughlan, G. F., \& Delahunt, E. (2014). Kinematic analysis of selected reach directions of the Star Excursion Balance Test compared with the Y-Balance Test. Journal of Sport Rehabilitation, 23, 27-35. 
Gribble, P. A., Delahunt, E., Bleakley, C., Caulfield, B., Docherty, C., Fourchet, F., et al (2013). Selection criteria for patients with chronic ankle instability in controlled research: A position statement of the International Ankle Consortium. British Journal of Sports Medicine, 48, $1014-1018$.

Gribble, P. A., Hertel, J., \& Denegar, C. R. (2007). Chronic ankle instability and fatigue create proximal joint alterations during performance of the Star Excursion Balance Test. International Journal of Sports Medicine, 28, 236-242.

Gribble, P. A., Hertel, J., Denegar, C. R., \& Buckley, W. E. (2004). The effects of fatigue and chronic ankle instability on dynamic postural control. Journal of Athletic Training, 39, 321-329.

Gribble, P. A., Hertel, J., \& Plisky, P. (2012). Using the Star Excursion Balance Test to assess dynamic postural-control deficits and outcomes in lower extremity injury: A literature and systematic review. Journal of Athletic Training, 47, 339-357.

Gutierrez, G. M., Jackson, N. D., Dorr, K. A., Margiotta, S. E., \& Kaminski, T. W. (2007). Effect of fatigue on neuromuscular function at the ankle. Journal of Sport Rehabilitation, 16, 295-306.

Hartsell, H. D., \& Spaulding, S. J. (1999). Eccentric/concentric ratios at selected velocities for the invertor and evertor muscles of the chronically unstable ankle. British Journal of Sports Medicine, 33, 255-258.

Hertel, J., Braham, R. A., Hale, S. A., \& Olmsted-Kramer, L. C. (2006). Simplifying the star excursion balance test: Analyses of subjects with and without chronic ankle instability. Journal of Orthopaedic and Sports Physical Therapy, 36, 131-137.

Hertel, J., Miller, S. J., \& Denegar, C. R. (2000). Intratester and intertester during the star excursion balance tests. Journal of Sport Rehabilitation, 9, 104.

Hoch, M. C., Staton, G. S., \& McKeon, P. O. (2011). Dorsiflexion range of motion significantly influences dynamic balance. Journal of Science and Medicine in Sport, 14, 90-92.

Hootman, J. M., Dick, R., \& Agel, J. (2007). Epidemiology of collegiate injuries for 15 sports: Summary and recommendations for injury prevention initiatives. Journal of Athletic Training, 42, 311-319.

Hubbard, T. J., \& Hertel, J. (2006). Mechanical contributions to chronic lateral ankle instability. Sports Medicine (Auckland, N. Z.), 36, $263-277$.

Linens, S. W., Ross, S. E., Arnold, B. L., Gayle, R., \& Pidcoe, P. (2014). Postural-stability tests that identify individuals with chronic ankle instability. Journal of Athletic Training, 49, 15-23.

Nawoczenski, D. A., Cook, T. M., \& Saltzman, C. L. (1995). The effect of foot orthotics on three-dimensional kinematics of the leg and rearfoot during running. Journal of Orthopaedic and Sports Physical Therapy, 21, 317-327.

Nogueira, D. V., Silva, S. B., de Abreu, L. C., Valenti, V. E., Fujimori, M., de Mello Monteiro, C. B., et al (2012). Effect of the rest interval duration between contractions on muscle fatigue. BioMedical Engineering OnLine, 11, 89.

Proske, U. (2005). What is the role of muscle receptors in proprioception? Muscle and Nerve, 31, 780-787.

Richie, D. H. Jr., (2001). Functional instability of the ankle and the role of neuromuscular control: A comprehensive review. The Journal of Foot and Ankle Surgery, 40, 240-251.

Riemann, B. L. (2002). Is there a link between chronic ankle instability and postural instability? Journal of Athletic Training, 37, 386-393.

Robinson, R., \& Gribble, P. (2008a). Kinematic predictors of performance on the Star Excursion Balance Test. Journal of Sport Rehabilitation, $17,347-357$.

Robinson, R. H., \& Gribble, P. A. (2008b). Support for a reduction in the number of trials needed for the star excursion balance test. Archives of Physical Medicine and Rehabilitation, 89, 364-370.

Willardson, J. M., \& Burkett, L. N. (2006). The effect of rest interval length on the sustainability of squat and bench press repetitions. Journal of Strength and Conditioning Research, 20, 400-403.

Willems, T., Witvrouw, E., Verstuyft, J., Vaes, P., \& De Clercq, D. (2002). Proprioception and muscle strength in subjects with a history of ankle sprains and chronic instability. Journal of Athletic Training, 37, 487-493.

Wright, C. J., Arnold, B. L., Ross, S. E., Ketchum, J., Ericksen, J., \& Pidcoe, P. (2013). Clinical examination results in individuals with functional ankle instability and ankle-sprain copers. Journal of Athletic Training, 48, 581-589.

Yeung, M. S., Chan, K. M., So, C. H., \& Yuan, W. Y. (1994). An epidemiological survey on ankle sprain. British Journal of Sports Medicine, $28,112-116$.

Yokoyama, S., Matsusaka, N., Gamada, K., Ozaki, M., \& Shindo, H. (2008). Position-specific deficit of joint position sense in ankles with chronic functional instability. Journal of Sports Science E' Medicine, 7, 480-485. 